\title{
Orthodontic management of a young girl with Class II div-1 malocclusion with spacing of upper anterior segment: A case report
}

\author{
Akther $\mathrm{K}^{1}$ BDS, Hossain MZ ${ }^{2}$ BDS, PhD
}

\begin{abstract}
We describe the treatment of a young girl age, 24 years, with class II division 1 malocclusion and spacing of upper anterior segment. Treatment consisted mainly of space closing, arch contraction, leveling and alignment with Edgewise fixed appliances by multiloop technique. Due to patient good cooperation, treatment time reduced (10 months). The treatment resulted in proper alignment of upper \& lower anterior segment, an ideal overjet, overbite and incisor angulations.
\end{abstract}

Key Words: Proclination, spacing, edgewise orthodontic therapy.

\section{INTRUDUCTION}

Class II is the most common \& difficult to treat malocclusion as compared to other malocclusions, due to its wide ranging varieties $\&$ interplay of various types of etiological factors. 1

It is important for every orthodontist to have adequate knowledge \& correct understanding of the various types of Class II malocclusions before instituting a treatment plan. There is no universal method of managing the condition. It is essential to have an adequate knowledge of normal growth pattern \& various cephalometric analysis for proper diagnosis \& treatment planning.

\section{CASE REPORT}

Case history: Sikha Khatun, age 24, came to the Department of Orthodontics \& Dentofacial Orthopedics at Dhaka Dental College \& Hospital for treatment. She had proclination and spacing of upper anterior segment. Patient's major reason for seeking treatment was to improve her dental esthetics and function. She complained of his ugly look during smile.

\section{Clinical examination}

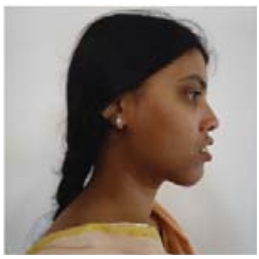

Profile-Right side

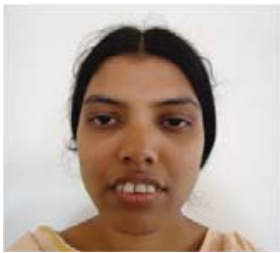

Facial photoFrontal view

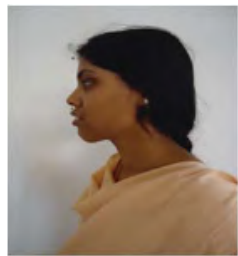

Profile-Left side
Shape of the hea Profile Analysis

Shape of the face

Facial symmetry

Lips

Upper lip line

Lower lip line

Naso-labial angle

Labio-mental depress

Temporo-Mandibular joint

Breathing

Deglutition

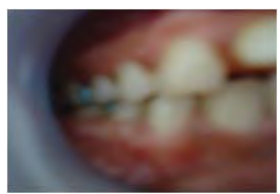

Intraoral view-

Right side
Brachycephalic

: Convex

: Oval

: Symmetrical

: Potentially competent

: Low

: Low

: Acute

: Normal

: Normal path of closure

: Nasal

: Normal

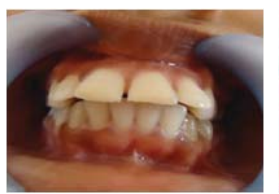

Intraoral

Anterior view

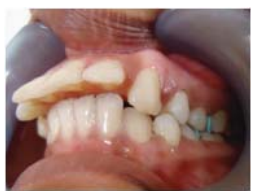

Intra oral viewLeft side

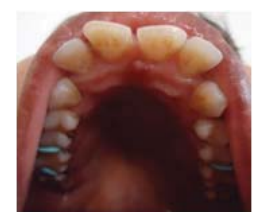

Upper

Occlusal view

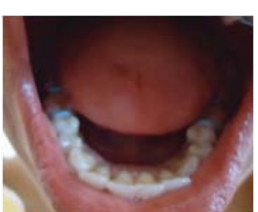

Lower

Occlusal view
Fig-2: Pre-treatment intra-oral photographs

Figure-1: Pre-treatment extra-oral facial photographs

\section{2}

1.Dr. Kohinur Akther, BDS, FCPS, Dept. of Orthodontics and Dentofacial Orthopedics, Dhaka dental College and Hospital, Mirpur-14, Dhaka-1206 2. Professor Dr. Mohammad Zakir Hossain, BDS, PhD, Professor and Head Deparment of Orthodontics, Dhaka Dental College and Hospital, Mirpur-14, Dhaka-1206 
The patient was in the permanent dentition. She presented with an overjet of $7 \mathrm{~mm}$, and the overbite was $3 \mathrm{~mm}$ and complete. Molar relationships were Class I on both sides, Canine \& Incisor relationship was Class-II div-1. Her oral hygiene was good.

\section{Model analysis:}

ARCH DISCREPANSY:

\begin{tabular}{|c|c|}
\hline Upper arch & Lower arch \\
\hline $\begin{array}{l}\text { Arch perimeter }- \text { Total tooth material } \\
=108 \mathrm{~mm}-104 \mathrm{~mm} \\
=4 \mathrm{~mm}\end{array}$ & $\begin{array}{l}\text { Arch perimeter -Total tooth material } \\
=90 \mathrm{~mm}--91 \mathrm{~mm} \\
=-1 \mathrm{~mm}\end{array}$ \\
\hline
\end{tabular}

\section{Remarks:}

Spacing in upper arch due to tooth tissue discrepancy.

\section{Radiographic examination:}
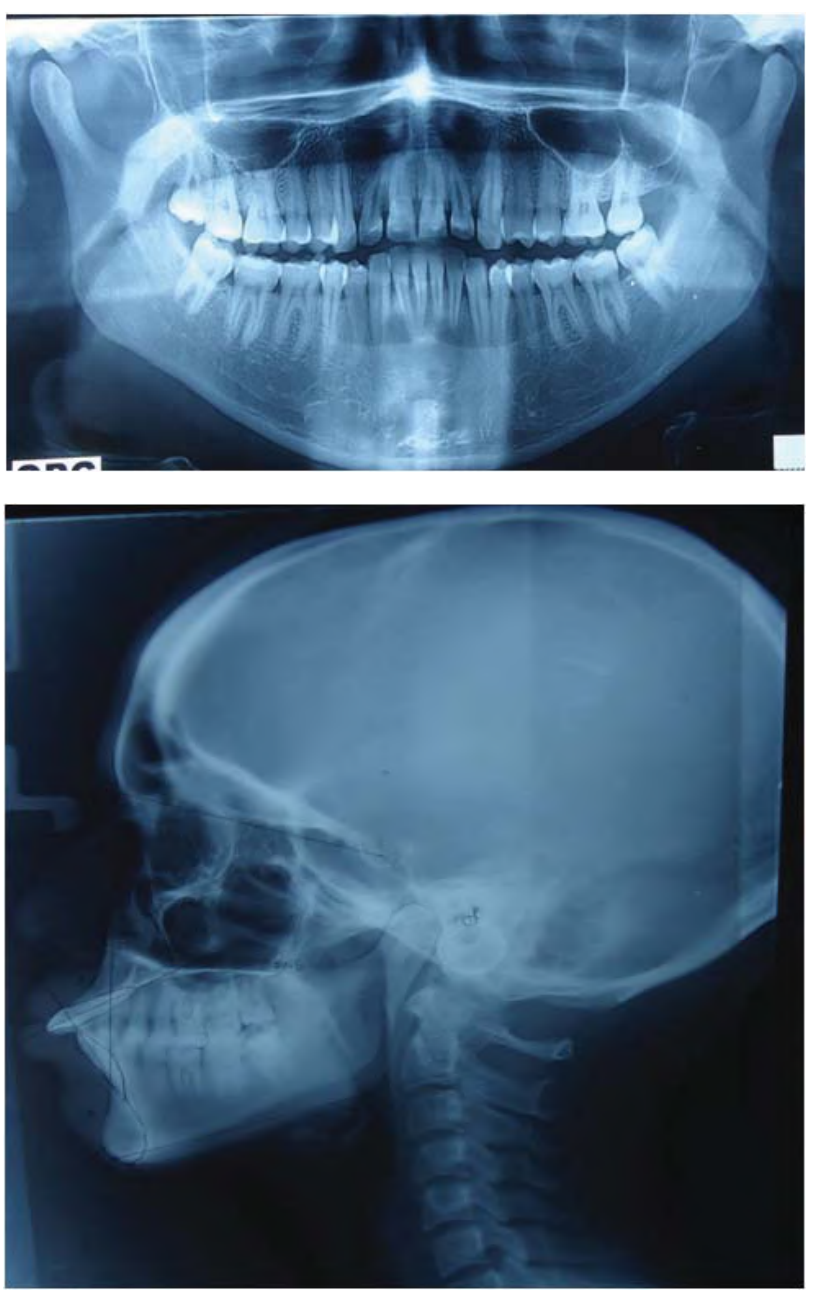

Fig-3: pre-treatment OPG and lateral cephalogram

\section{TREATMENT OBJECTIVES}

The following treatment objectives were established:

1. Arch contraction of maxillary anterior segment that will result normal overjet $\&$ overbite

2. Improvement of aesthetics by the correction of lip posture \& facial profile

3. Improvement of functional demand by correcting better occlusal interdigitation.

\section{Treatment plan:}

1. Initial alignment and leveling of upper and lower jaw

2. Retraction of upper canines

3. Contraction of upper arch.

\section{Treatment sequence/ progression:}

1. TPA for increase anchorage value

2. Upper multibond edgewise technique

3. Canine retraction by 0.016 inch S.S. arch wire

4. Arch contraction by $0.017 \times 0.025$ inch S.S. rectangular wire

5. Retention by Hawley retainer.

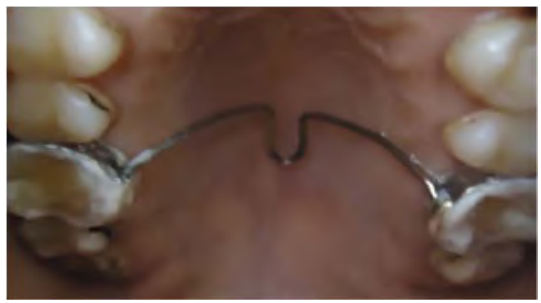

Fig 4: TPA is inserted for anchorage demand. 


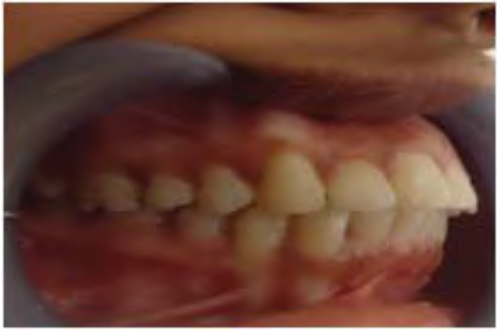

Intraoral view-Right side

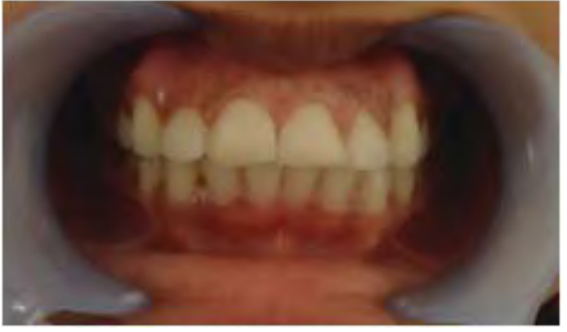

Intraoral Anterior view

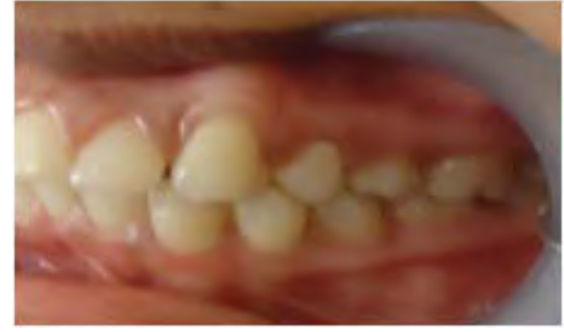

Intraoral view-Left side

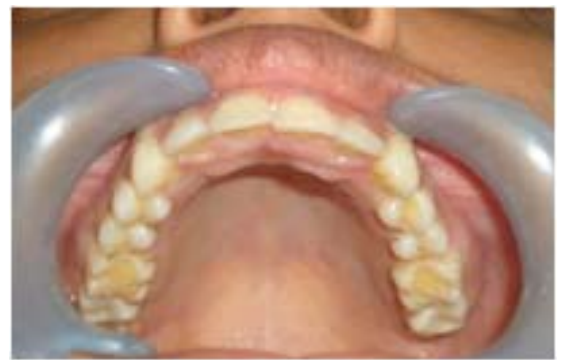

Upper Occlusal view

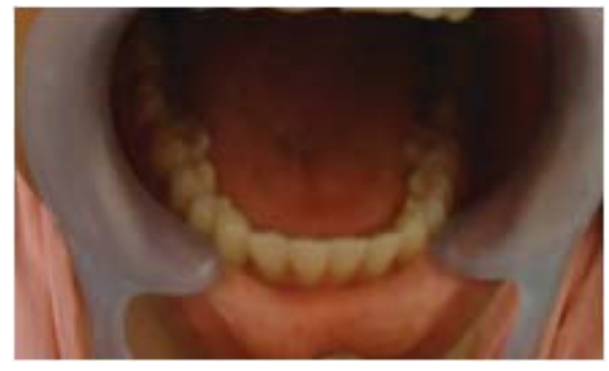

Lower Occlusal view

Fig 5: Post-treatment intra-oral photograph
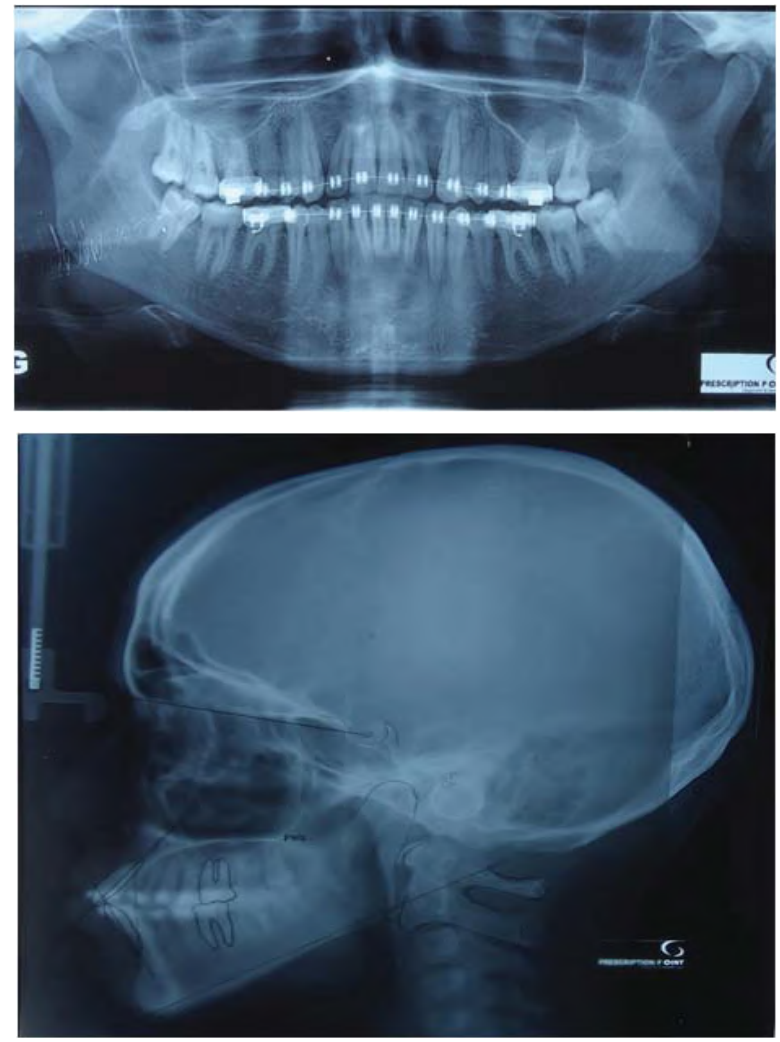

Fig 6: After treatment OPG and lateral cephalogram 
Pre and post treatment cephalogram analyses:

\begin{tabular}{|c|c|c|c|c|}
\hline Parameters & $\begin{array}{l}\text { Reference } \\
\text { value } \\
\text { (Caucasians) } \\
\text { Ref: Om P Kharbanda. } \\
\text { Orthodontics Diagnosis and } \\
\text { Management of } \\
\text { Malocclusion and } \\
\text { Dentofacial Deformities,: } \\
\text { Elsevier } 2009 \text { edition. }\end{array}$ & $\begin{array}{l}\text { Reference } \\
\text { Value } \\
\text { (Bangladeshi) } \\
\text { Ref: Rizvi HM, Hossain } \\
\text { MZ. Cephalometric } \\
\text { norms of young adults of } \\
\text { Bangladesh ( Steiner's } \\
\text { analysis )- priliminary } \\
\text { report. Bangladesh } \\
\text { journal of Orthodontics } \\
\text { and Dentofacial } \\
\text { Orthopedics, 2011, Vol 2, } \\
\text { No 1, 13. }\end{array}$ & $\begin{array}{l}\text { Pre-treatment } \\
\text { measurement }\end{array}$ & $\begin{array}{l}\text { Post-treatment } \\
\text { measurement }\end{array}$ \\
\hline SNA $^{\circ}$ & $82^{\circ}$ & $83.8^{\circ}$ & $83^{\circ}$ & $84^{\circ}$ \\
\hline $\mathrm{SNB}^{\circ}$ & $80^{\circ}$ & $81.5^{\circ}$ & $79^{\circ}$ & $80^{\circ}$ \\
\hline $\mathrm{ANB}^{\circ}$ & $2^{\circ}$ & $2.3^{\circ}$ & $4^{\circ}$ & $4^{\circ}$ \\
\hline IIA $^{\circ}$ & $131^{\circ}$ & $117.7^{\circ}$ & $95^{\circ}$ & $116^{\circ}$ \\
\hline $\mathrm{U} 1$ to $\mathrm{NA}^{\circ}$ & $22^{\circ}$ & $29.8^{\circ}$ & $30^{\circ}$ & $30^{\circ}$ \\
\hline $\mathrm{U} 1$ to NA mm & $4 \mathrm{~mm}$ & $8 \mathrm{~mm}$ & $7 \mathrm{~mm}$ & $7 \mathrm{~mm}$ \\
\hline $\mathrm{L} 1$ to $\mathrm{NB}^{\circ}$ & $25^{\circ}$ & $30.6^{\circ}$ & $30^{\circ}$ & $25^{\circ}$ \\
\hline $\mathrm{L} 1$ to $\mathrm{NB} \mathrm{mm}$ & $4 \mathrm{~mm}$ & $8 \mathrm{~mm}$ & $6 \mathrm{~mm}$ & $6 \mathrm{~mm}$ \\
\hline
\end{tabular}

Pre-treatment

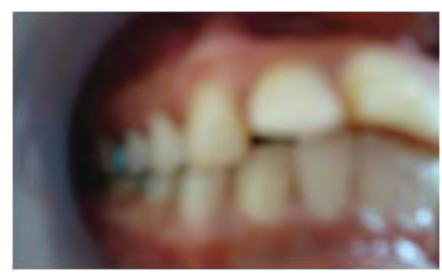

Intraoral view -Right side

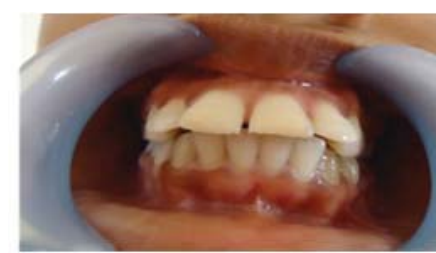

Intraoral view -anterior

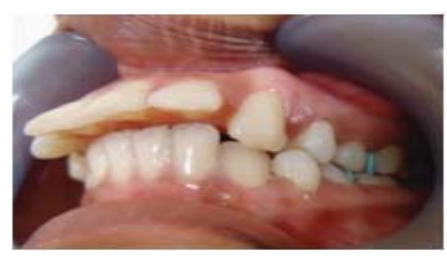

Intraoral view-Left side
Post-treatment

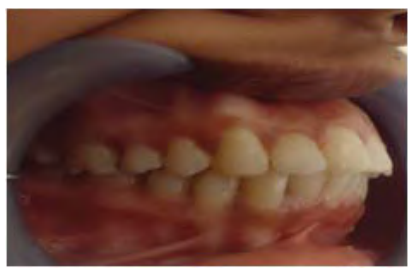

Intraoral view -Right side

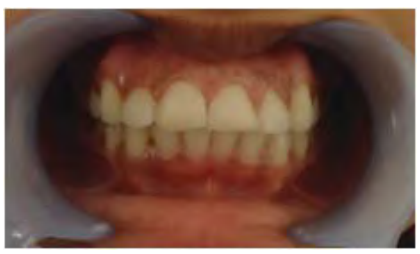

Intraoral view -anterior

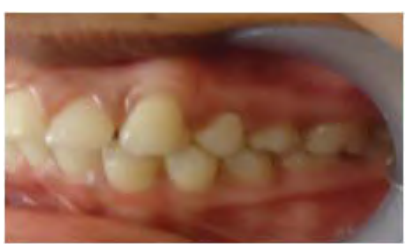

Intraoral view -Left side

Fig7: Pre and Post treatment intra oral photographs 
Pre-treatment

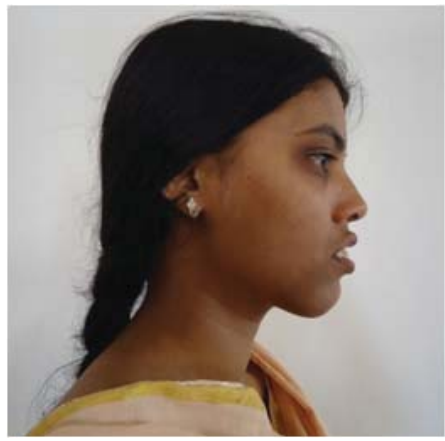

Profile-Right side

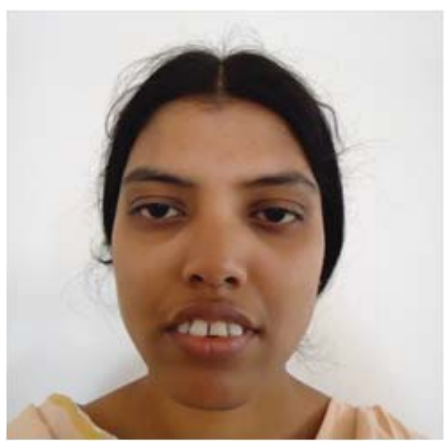

Facial photo-Frontal view

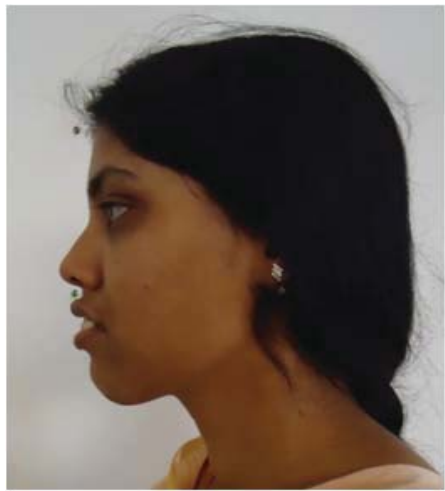

Profile-Left side
Post-treatment

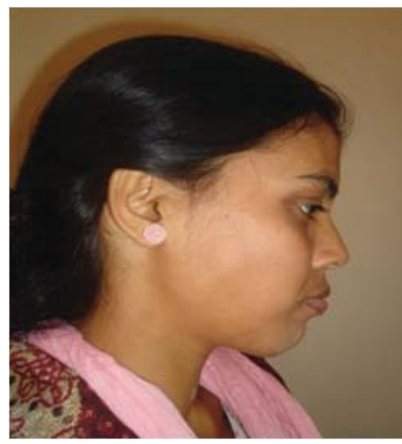

Profile-Right side

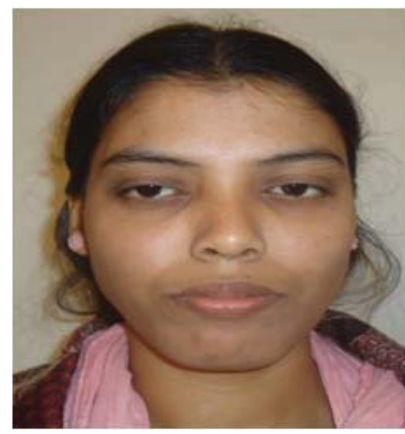

Facial photo-Frontal view

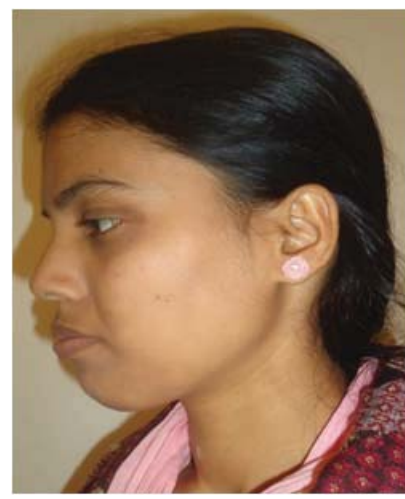

Profile-Left side

Fig 8: Pre and Post treatment extra oral photographs 


\title{
DISCUSSION:
}

One of the most common problems in orthodontics today is Class II div-1 malocclusion. This patient was treated with space closing, arch contraction and light edgewise forces to produce a result that was pleasing to the patient and satisfying to the orthodontists in a one year period.

\section{CONCLUSION}

Analysis of final records indicated that all treatment objectives were achieved. The teeth were placed in good alignment, spacing and proclination were relieved \& good occlusion was maintained. A satisfactory esthetic result had been achieved. The parent \& patients psychological satisfaction was also achieved.

\section{REFERENCES:}

1. Singh G. Classification of malocclusion: Textbook of Orthodontics. 2nd ed. 159-174, 2007.

2. Hossain MZ. A clinical and practical sequence in the management of Angle Class II malocclusion: Ban J Orthod and Dentofac Orthop, October 2010; Vol-1, No. 1, 27-37.

3. Tweed, C. H.: Indications for the extraction of teeth in orthodontic procedure, AM. J. ORTHOD. ORAL SURG. 30: 405-428, 1944.

4. McDougall, P. D., McNamara, J. A., Jr., and Dierkes, J. M.: Arch width development in Class II patients treated with the Fränkel appliance, AM. J. ORTHOD. 82: 10-22, 1982.

5. Proffit WR. Fields H W. , Contemporary Orthodontics. 4th ed. St Louis; Mosby; 2001.

\section{Correspondence}

\author{
Dr. Kohinur Akther \\ BDS, FCPS \\ Dept. of Orthodontics and Dentofacial Orthopedics \\ Dhaka dental College and Hospital \\ Mirpur-14, Dhaka-1206 \\ Mobile: +8801712114053, E-mail:kohinurpoly@yahoo.com
}

